\title{
(6) OPEN ACCESS \\ Cross-shift study of exposure-response relationships between bioaerosol exposure and respiratory effects in the Norwegian grain and animal feed production industry
}

\author{
Anne Straumfors, ${ }_{1}^{1}$ Kari Kulvik Heldal, ${ }^{1}$ Wijnand Eduard, ${ }^{1}$ Inge M Wouters, ${ }^{2}$ \\ Dag G Ellingsen, ${ }^{1}$ Marit Skogstad ${ }^{3}$
}

1 Department of Chemical and Biological Work Environment, National Institute of Occupational Health, Oslo, Norway

${ }^{2}$ Faculty of Veterinary Medicine, Institute of Risk Assessment Sciences, Utrecht University, Utrecht, The Netherlands

${ }^{3}$ Department of Occupational Medicine and Epidemiology, National Institute of Occupational Health, Oslo, Norway

\section{Correspondence to} Dr Anne Straumfors, Department for the Chemica and Biological Work Environment, National Institute of Occupational Health, P.O. Box 8149 Dep, Oslo 0033 Norway; anne.straumfors@ stami.no

Received 12 November 2015 Revised 24 May 2016 Accepted 12 June 2016 Published Online First 29 July 2016

\section{ABSTRACT}

Objective We have studied cross-shift respiratory responses of several individual bioaerosol components of the dust in the grain and feed industry in Norway.

Methods Cross-shift changes in lung function and nasal congestion, as well as in respiratory and systemic symptoms of 56 exposed workers and 36 referents, were recorded on the same day as full-shift exposure to the inhalable aerosol fraction was assessed. Exposureresponse associations were investigated by regression analysis.

Results The workers were exposed on average to $1.0 \mathrm{mg} / \mathrm{m}^{3}$ of grain dust, $440 \mathrm{EU} / \mathrm{m}^{3}$ of endotoxin, $6 \mu \mathrm{g} / \mathrm{m}^{3}$ of $\beta-1,3$-glucans, $17 \times 10^{4} / \mathrm{m}^{3}$ of bacteria and $4 \times 10^{4} / \mathrm{m}^{3}$ of fungal spores during work. The exposure was associated with higher prevalence of self-reported eye and airway symptoms, which were related to the individual microbial components in a complex manner. Fatigue and nose symptoms were strongest associated with fungal spores, cough with or without phlegm was associated with grain dust and fungal spores equally strong and wheeze/tight chest/dyspnoea was strongest associated with grain dust. Bioaerosol exposure did not lead to cross-shift lung function decline, but several microbial components had influence on nose congestion. Conclusions Exposure to fungal spores and dust showed stronger associations with respiratory symptoms and fatigue than endotoxin exposure. The associations with dust suggest that there are other components in dust than the ones studied that induce these effects.

\section{What this paper adds}

- Occupational exposure to grain dust may induce respiratory symptoms in grain handlers, but the dose-response patterns between grain dust exposure and inflammatory response or changes in respiratory function are not consistent between studies. This may be due to differential effects of individual grain dust components, such as mycotoxins, tannins, lectins, endotoxins, fungal spores and $\beta$-1,3-glucans, and differences in grain dust composition.

- This is the first study in the grain and animal feed industry that has investigated the cross-shift respiratory response to exposure for several individual bioaerosol components of the grain dust.

- Bioaerosol exposure did not lead to cross-shift lung function decline, but several microbial components were associated with nose congestion and self-reporting of symptoms in a complex manner.

- Exposure to fungal spores and grain dust showed stronger associations with respiratory effects and fatigue than endotoxin exposure.

- The strong associations with grain dust suggest that there are other components in grain and feed dust than the ones studied that induce respiratory effects and that remain to identify.

\section{INTRODUCTION}

Grain dust exposure may induce respiratory symptoms in grain handlers, and measures for reducing the dust exposure have constantly attention in the grain industry. Employees at grain elevators and compound feed mills may be exposed to large amounts of grain dust, ${ }^{1}$ frequently leading to symptoms from the airways and pulmonary functional changes such as asthma. ${ }^{2}$ Acute and short-term effects, such as cross-shift lung function decline and toxic pneumonitis, have been observed during a workday, ${ }^{3-6}$ and long-term exposure may lead to permanently decreased lung function, ${ }^{7-9}$ although results are not always consistent. ${ }^{10} 11$

The pathological response to grain dust exposure suggests inflammatory and allergic pathways, although exact mechanisms are under debate. The cell wall component of Gram-negative bacteria, endotoxin, has potential to exert several of the observed health effects caused by grain dust exposure, ${ }^{12}$ and many studies from the grain industry include endotoxin measurements. On the basis of in vitro studies, animal experiments and epidemiological studies, endotoxin has been proposed as a target for measurements of occupational health hazards related to grain dust exposure. ${ }^{13}$ However, grain dust also contains several other components, such as mycotoxins, tannins, lectins, lymphocyte mitogens and $\beta-1,3-d$-glucans, that may induce immunological, allergic or toxic responses, and interact with the effects of endotoxin. ${ }^{12}$ 
The dose-response patterns between grain dust exposure and inflammatory response or changes in respiratory function are contradictory between studies, possibly due to a differential effect of the individual grain dust components. Furthermore, the microbial composition of the dust will vary between crop types, years/weather conditions, geographic regions, companies and job groups. ${ }^{14}$ This exposure variability may dilute and even bias exposure-response patterns, and should therefore be considered. Few exposure studies in the grain and animal feed industry have included microbial components, and studies of lung function have been conducted without exposure measurements. Only few exposure-response studies have assessed exposure simultaneously with health examinations. To the best of our knowledge, no study has reported exposure-response associations of other exposure components than grain dust and endotoxins. Thus, information on exposure-response associations with other bioaerosol components is needed to understand health effects after grain dust exposure.

Effects of grain dust exposure on nose congestion by the use of acoustic rhinometry (AR) have, to the best of our knowledge, not been studied before. AR provides objective measurements of the cross-sectional area and volume of the nasal cavity, which may reveal inflammatory responses reflected as swelling of the nose mucosa. ${ }^{15}$

In the present study, we therefore aimed to investigate the cross-shift respiratory response of grain dust exposure, and their associations with individual bioaerosol components of the dust. Cross-shift lung function, nasal congestion and symptoms were recorded on the same day as full-shift exposure to inhalable grain dust, endotoxin, bacteria, fungal spores and $\beta-1,3$-glucans were assessed.

\section{MATERIALS AND METHODS}

\section{Company and job description}

Twenty companies of grain elevators and compound feed mills in the Norwegian grain industry geographically distributed throughout 20 municipalities in 9 counties in central and southeastern Norway were included in this study. Recruitment and description of companies and work tasks is previously published. ${ }^{14}$

\section{Study population}

The study population comprised all employees working day shifts; altogether, 68 grain dust exposed workers and 38 assumed unexposed administrative workers as referents. Two workers assigned to the reference group were excluded because of health reasons they had been replaced from exposed jobs to office work, leaving 36 referents. The exposed workers included 28 workers in the grain elevator department, 17 workers in the compound feed mill department, 6 workers in grain elevator and compound feed mill departments and 5 in transport workers. Characteristics of the study population are given in table 1. All participants gave their written informed consent on participation in the study. All, but one, of the workers who received the written information agreed to participate. The one who denied participated in the exposure measurements only. The Regional Ethical Committee of South-East Norway and the Norwegian Data Inspectorate approved the study.

\section{Study design}

The field team rigged the equipment at the work site and informed the participating workers on a Monday, and performed exposure measurements and health examinations on a Tuesday. For two companies, exposure measurements and health
Table 1 Characteristics of the study population of grain and animal feed industry workers in Norway

Exposed workers $(n=68) \quad$ Referents $(n=36)$

\begin{tabular}{|c|c|c|}
\hline Age (year)* & $41(16-61)$ & $46(21-60)$ \\
\hline Height $(\mathrm{cm})^{*}$ & 179 (162-196) & $176(156-191)$ \\
\hline Weight $(\mathrm{kg})^{*}$ & $90(63-123)$ & $83(55-109)$ \\
\hline Body mass index $\left(\mathrm{kg} / \mathrm{m}^{2}\right)^{*}$ & $28(21-38)$ & $27(21-38)$ \\
\hline Never-smoker $(\%) \dagger$ & 43 & 44 \\
\hline Current smoker (\%) $\dagger$ & 27 & 17 \\
\hline Ex-smoker (\%)† & 31 & 39 \\
\hline Male/female (\%) & $94 / 6$ & $83 / 17$ \\
\hline Atopy‡ (\%)† & 22 & 23 \\
\hline Physician-diagnosed asthma§ & $3(4)$ & $2(6)$ \\
\hline Farm childhood (\%)+ๆ & 35 & 42 \\
\hline Farm or animals at home $(\%) \dagger$ & 16 & 28 \\
\hline RPE use $(\%) \dagger$ & 16 & 0 \\
\hline FVC $(L)^{* *}$ & $5.1(3.3-8.4)$ & $4.9(3.3-7.1)$ \\
\hline FVC\% pred** & $96(66-133)$ & $100(80-122)$ \\
\hline $\mathrm{FEV}_{1}(\mathrm{~L})^{* *}$ & $4.0(2.7-6.6)$ & $3.7(1.7-5.4)$ \\
\hline $\mathrm{FEV}_{1} \%$ pred $^{* *}$ & $92(68-127)$ & $93(51-120)$ \\
\hline $\mathrm{FEV}_{1} / \mathrm{FVC} \%$ ** & $78(68-90)$ & 76 (48-89) \\
\hline $\mathrm{D}_{\mathrm{L}, \mathrm{co}}(\operatorname{adj})(\mathrm{mmol} / \mathrm{min} / \mathrm{kPa})^{* *}$ & $9.7(6.3-14.6)$ & $8.8(3.3-12.6)$ \\
\hline $\mathrm{D}_{\mathrm{L}, \mathrm{CO}} \%$ pred** & $86(32-149)$ & $85(58-127)$ \\
\hline D-factor** & $0.6(0.1-1.8)$ & $0.5(0.1-1.2)$ \\
\hline
\end{tabular}

${ }^{*} \mathrm{AM}$ (minimum-maximum).

†Prevalence.

$\ddagger$ Positive serum reaction towards inhalation panel.

$\S$ Self-reported, expressed as $n(\%)$.

qIncluded one exposed worker that moved to a farm in his youth.

** Lung function at baseline is expressed as AM (minimum-maximum) of actual values and mean per cent of predicted values according to age, height and weight, whereas the nose congestion factor is expressed as AM (minimum-maximum) of a relative value. $A M$, arithmetic mean; $C O$, carbon monoxide; $D_{L, C o}$ (adj), $C O$ diffusion capacity of the lung adjusted for the haemoglobulin concentration; D-factor, decongestion factor of the nose; $F_{E V}$, forced expired volume in the first second; FVC, forced vital capacity; RPE, respiratory protective equipment.

examinations were performed on a Wednesday. The employees were examined before work (baseline) and after work in a cross-shift design. The examinations included spirometry, gas diffusion tests and AR. The employees were asked to abstain from smoking at least 1 hour before the health examinations. Blood samples were collected after shift for atopy testing and haemoglobin measurements. After work, the employees filled in a questionnaire reporting possible work-related health complaints that day or last week. Thirteen referents and 25 exposed workers were examined over, respectively, 3 and 5 months in the winter, whereas 23 referents and 43 exposed workers were examined over, respectively, 3 and 5 months in the autumn of 2008 .

\section{Aerosol exposure measurements and analyses}

Fifty-six full-shift personal inhalable samples were collected with PAS-6 personal inhalable samplers ${ }^{16}$ and portable pumps (PS101; National Institute of Occupational Health, Oslo, Norway) for $6-8$ hours with a flow rate of $2 \mathrm{~L} / \mathrm{min}$. Samples were analysed for grain dust, endotoxins, bacteria, fungal spores and $\beta-1,3$-glucans as previously described. ${ }^{1}$ In brief, dust was weighed, bacteria were stained with acridine orange and counted by epifluorescence microscopy, fungal spores were counted by scanning electron microscopy, endotoxins were analysed by Limulus amoebocyte lysate assay and $\beta-1,3$-glucans were analysed by enzyme immunoassay. The job groups and exposure variability have been described previously. ${ }^{1}{ }^{14}$ 


\section{Questionnaire}

After work shift, the participants filled out a questionnaire based on the ATS recommended respiratory disease questionnaire for epidemiological research ${ }^{17}$ that included questions on respiratory protective equipment (RPE) use, smoking habits, work history, symptoms of the airways, eyes, skin and gastrointestinal and systemic symptoms experienced during or after work on the day of the examinations. A member of the research team was available for questions from the participants.

\section{Spirometry}

After demonstration of the procedure, the spirometry tests were performed with a Jaeger Master screen PFT spirometer (Erich Jaeger GmbH \& Co. KG, Würtzburg, Germany) according to the ATS/ERS 2005 criteria with the person sitting and breathing through the mouth piece using a nose clip. ${ }^{18}$ The spirometer was calibrated daily with a $3 \mathrm{~L}$ syringe. The best of any three efforts, regardless of curve, of the forced vital capacity (FVC) and the forced expired volume in the first second $\left(\mathrm{FEV}_{1}\right)$ were used in the analyses. Results of five and six workers before and after shift, respectively, were excluded due to technical reasons. Ninety-five of the 104 workers had acceptable tests before and after shift (91\%). $\mathrm{FEV}_{1} / \mathrm{FVC}$ and the percentage of the predicted values for $\mathrm{FEV}_{1}$ ( $\mathrm{FEV}_{1} \%$ predicted) and $\mathrm{FVC}$ (FVC\% predicted) were calculated using reference values for a normal population from central Norway. ${ }^{19}$ Lung function at baseline is expressed as arithmetic mean (AM) (minimum-maximum) of actual values in $\mathrm{L}$, and mean per cent of predicted values according to age, height and weight. Cross-shift changes in lung function are expressed in $\mathrm{mL}$.

\section{Gas diffusion tests}

The transfer factor for pulmonary carbon monoxide (CO) uptake was measured by single-breath $\mathrm{CO}$ diffusion (Jaeger Master Screen PFT, Erich Jaeger GmbH \& Co. KG) according to the ATS/ERS 2005 criteria. $^{20}$ Tests of seven workers before and after shift were excluded due to technical reasons. Ninety workers had acceptable tests before and after shift (87\%). The $\mathrm{CO}$ diffusion capacity of the lung $\left(\mathrm{D}_{\mathrm{L}, \mathrm{CO}}\right)$ was adjusted for the concentration of haemoglobulin ${ }^{21}$ and expressed as $\mathrm{mmol} / \mathrm{min} /$ $\mathrm{kPa}$. Reference values of the European Coal and Steel Community were used. ${ }^{22}$ The mean of two $\mathrm{D}_{\mathrm{L}, \mathrm{CO}}$ tests was used in the analyses. The alveolar volume was estimated by using the helium dilution method.

\section{Acoustic rhinometry}

The nasal cavity dimensions were measured by AR (Rhin2100, Rhino Metrics AS, Lynge, Denmark) with the worker in a seated position, using a hand-held sound wave tube and an anatomical nasal adapter. The mean of three independent measurements with a coefficient of variation $<5 \%$ was used for calculations. The total nasal volume and cross-sectional areas were calculated as the sum of both nasal cavities, in order to minimise bias from the nasal cycle. The smallest total cross-sectional area and the total volume between 0-20 mm (anterior; 1) and 20-50 mm (interior; 2) from the nostrils were called TMCA1 and TMCA2, and TVOL1 and TVOL2, respectively. Measurements were performed in the morning before work, after work and $15 \mathrm{~min}$ after decongestion with three sprays in each nostril of $1 \mathrm{mg} / \mathrm{mL}$ xylometazoline (Otrivin, Novartis Consumer Health, Norway) in order to measure basal dimensions. The degree of mucosal swelling was estimated by the decongestion factor (D-factor) computed as follows: ${ }^{23}$

Decongestion $_{\text {factor }}=\left(\right.$ TVOL $\left.2_{\text {after decongestion }}-\mathrm{TVOL} 2_{\text {before decongestion }}\right)$ /TVOL $2_{\text {before decongestion }}$

A decongestion factor between 0.2 and 0.4 is regarded normal, $0.4-0.7$ indicates a moderate swelling and above 0.7 is regarded severe. A complete set of tests were obtained for 97 workers (93\%).

\section{Blood samples}

Blood for haemoglobulin analysis was collected in vacutainers containing EDTA, whereas that for atopy testing was collected in vacutainers without additives. The blood samples were left at room temperature for 30-90 min. Serum was isolated from the blood samples in tubes without additives by 10 min centrifugation at $3500 \mathrm{rpm}$ followed by careful pipetting of serum into new tubes. The serum and the EDTA-blood samples were sent directly to a commercial routine laboratory for analysis. Atopy was defined by the presence of specific serum immunoglobulin $\mathrm{E}$ antibodies towards one or more allergens in a panel of typical outdoor airway allergens (birch, timothy, mugwort, Alternaria tenious and Cladosporium herbarum) determined by Phadiatop screening (Fürst Laboratories, Oslo, Norway).

\section{Statistical analysis}

Observations of workers not using RPE on the day of investigation were selected $(n=92)$. Differences in symptom prevalence between exposed workers and referents were tested by Pearsons $\chi^{2}$ test, and a $p$ value of $\leq 0.05$ was considered statistically significant. Exposure differences between job groups were tested by comparing geometric means (GM) in independent sample $t$ tests. Associations between exposure and cross-shift respiratory changes or symptoms were investigated by using individual bioaerosol exposure values. The exposure values were used categorised at three levels and as continuous variables after $\log _{10}$-transformation. Associations with cross-shift changes in lung function or nose congestion were investigated using univariate general linear models with the health parameter as independent, linear exposure variables as dependent covariates and categorical exposure variables as fixed factors. Associations with self-reported symptoms were investigated by logistic regression models. Before logistic regression analyses, all nose symptoms, all eye symptoms, cough+cough with phlegm and all pulmonary symptoms, respectively, were grouped. Confounding effects of age, gender smoking, atopy, farm childhood and contact with farm and pet animals were tested and included in the models when the effect was significant, that is, at a $\mathrm{p}$ value of below 0.05 and when changing the $\beta$ coefficient $>20 \%$.

\section{RESULTS}

\section{Bioaerosol exposure}

The GM and SD (geometric standard deviation (GSD)) of dust exposure of all workers was $1.0 \mathrm{mg} / \mathrm{m}^{3}$ (2.9). The highest exposure was observed in compound feed mills (GM $1.6 \mathrm{mg} / \mathrm{m}^{3}$, GSD 4.0, table 2).

The GM (GSD) concentration of endotoxin was 444 (4.8) $\mathrm{EU} / \mathrm{m}^{3}, \beta-1,3$-glucans $6(4.6) \mu \mathrm{g} / \mathrm{m}^{3}$, bacteria $17 \times 10^{4} / \mathrm{m}^{3}$ (5.9) and fungal spores $4 \times 10^{4} / \mathrm{m}^{3}$ (3.3). The highest concentrations of all components were in the grain elevator department, except bacterial exposure, which was highest among transport 
Table 2 Aerosol exposure of grain and animal feed industry workers in Norway not using respiratory protective equipment

\begin{tabular}{|c|c|c|c|c|c|}
\hline Aerosol exposure & All job groups & Grain elevator & Compound feed mill & Grain elevator and feed mill & Grain transport \\
\hline $\mathrm{N}$ & 56 & 28 & 17 & 6 & 5 \\
\hline \multicolumn{6}{|l|}{ Grain dust $\left(\mathrm{mg} / \mathrm{m}^{3}\right)$} \\
\hline GM (GSD) & $1.0(2.9)$ & $0.9(2.5)^{\mathrm{a}}$ & $1.6(4.0)^{\mathrm{abc}}$ & $0.5(1.8)^{c}$ & $0.5(2.0)^{b}$ \\
\hline 25th centile & 0.5 & 0.6 & 0.6 & 0.3 & 0.3 \\
\hline 75th centile & 2.0 & 1.4 & 4.4 & 0.9 & 0.9 \\
\hline Minimum-maximum & $0.09-14$ & $0.1-7.0$ & $0.09-14$ & $0.2-1.0$ & $0.3-1.5$ \\
\hline \multicolumn{6}{|l|}{ Endotoxin $\left(\mathrm{EU} / \mathrm{m}^{3}\right)$} \\
\hline GM (GSD) & $444(4.8)$ & $852(3.9)^{\mathrm{ab}}$ & $348(3.4)^{\mathrm{a}}$ & $107(5.0)^{b}$ & $146(7.6)$ \\
\hline 25th centile & 194 & 395 & 229 & 18 & 48 \\
\hline 75th centile & 1306 & 1700 & 766 & 428 & 670 \\
\hline Minimum-maximum & $15-10940$ & $15-10940$ & $26-2700$ & $17-530$ & $41-5320$ \\
\hline \multicolumn{6}{|l|}{ Bacteria $\left(\times 10^{4} / \mathrm{m}^{3}\right)$} \\
\hline GM (GSD) & $17(5.9)$ & $25(6.8)^{\mathrm{a}}$ & $18(3.3)^{b}$ & $2(5.5)^{\mathrm{abc}}$ & $30(2.5)^{c}$ \\
\hline 25th centile & 6.5 & 13 & 7 & 0.3 & 16 \\
\hline 75th centile & 55 & 96 & 33 & 10 & 58 \\
\hline Minimum-maximum & $0.3-240$ & $0.3-230$ & $1-240$ & $0.3-15$ & $11-130$ \\
\hline \multicolumn{6}{|l|}{ Fungal spores $\left(\times 10^{4} / \mathrm{m}^{3}\right)$} \\
\hline GM (GSD) & $4(3.3)$ & $4(3.7)$ & $3(3.1)$ & $3(2.9)$ & $3(2.3)$ \\
\hline 25th centile & 1.4 & 1.3 & 1.5 & 1.3 & 1.4 \\
\hline 75th centile & 8 & 21 & 4 & 5.4 & 6.5 \\
\hline Minimum-maximum & $1.0-50$ & $1.1-48$ & $1.1-50$ & $1.3-20$ & $1.0-7.8$ \\
\hline \multicolumn{6}{|l|}{$\beta$-1,3-Glucans $\left(\mu \mathrm{g} / \mathrm{m}^{3}\right)$} \\
\hline GM (GSD) & $6(4.6)$ & $11(3.9)^{\mathrm{a}}$ & $5(4.1)^{b}$ & $1(2.5)^{\mathrm{ab}}$ & $2(6.0)$ \\
\hline 25th centile & 2.3 & 4 & 2 & 0.6 & 0.6 \\
\hline 75th centile & 19 & 23 & 15 & 3.2 & 12 \\
\hline Minimum-maximum & $0.3-151$ & $0.3-151$ & $0.4-42$ & $0.4-3$ & $0.6-40$ \\
\hline
\end{tabular}

GMs with identical letters are significantly different $(p \leq 0.05)$.

$\mathrm{GM}$, geometric means.

workers $\left(30 \times 10^{4} / \mathrm{m}^{3}(2.5)\right.$, table 2). Endotoxin and $\beta$-1,3-glucan exposure levels were strongly correlated (Pearson correlation coefficient $r_{P}=0.93$ ), whereas moderate correlations were observed between $\beta$-1,3-glucan and dust, between $\beta$-1,3-glucan and fungal spores and between endotoxin and grain dust exposure levels $\left(\mathrm{r}_{P}=0.59-0.66\right)$. Endotoxin, bacteria and $\beta$-1,3-glucan levels were 3.5-4 times higher for workers using RPE compared with those who did not ( $\mathrm{p} \leq 0.02$ for all), whereas the exposure level for grain dust and fungal spores was similar (not shown).

\section{Self-reported symptoms}

Exposed workers reported health complaints after work shift more frequently than referents (table 3 ). The prevalence of fever attack $(p=0.04)$, cough $(p=0.03)$, wheezing $(p=0.04)$ and eye itch/sting $(p=0.04)$ was significantly more often reported by exposed workers than that by referents. Only exposed workers reported fever attacks, wheezing and hand itch/sting. Nearly all symptoms were reported by workers not using RPE (not shown). Workers without RPE were selected for further analysis of exposure-response associations in order to avoid overestimation of exposure levels. One exposed worker who had not denoted RPE usage was excluded.

Individuals exposed to grain dust above $1.3 \mathrm{mg} / \mathrm{m}^{3}$ reported significantly more cough with or without phlegm (OR 5.5), wheezing/tight chest/dyspnoea (OR 4.0) and eye symptoms (OR 7.3) than the referents (table 4). Cough and cough with phlegm was reported more often among workers exposed to endotoxin above $1200 \mathrm{EU} / \mathrm{m}^{3}$ (OR 5.7), fungal spores above $5.5 \times 10^{4} / \mathrm{m}^{3}$ (OR 5.0) and $\beta$-1,3-glucans above $19 \mu \mathrm{g} / \mathrm{m}^{3}$ (OR 9.0), compared with referents. Eye symptoms were also reported more often in workers exposed to endotoxin levels above $360 \mathrm{EU} / \mathrm{m}^{3}$ (OR 6.4, $\mathrm{p} \leq 0.05$ ), $\quad \beta$-1,3-glucan exposure above $3.7 \mu \mathrm{g} / \mathrm{m}^{3}$ (OR 6.4, $\mathrm{p} \leq 0.05)$ and fungal spore exposure between $1.6 \times 10^{4} / \mathrm{m}^{3}$ and $5.4 \times 10^{4} / \mathrm{m}^{3}$ (OR 6.1), but not significantly in the highest fungal exposure category (OR 3.9).

Additionally, workers grouped in the highest exposure category of endotoxin, fungal spores and $\beta-1,3$-glucans reported more fatigue than referents (OR 3.0-3.5, table 4), although only the association with $\beta-1,3$-glucans was significantly different from the referents. Linear exposure-response associations between reported symptoms and some $\log _{10}$-transformed bioaerosol concentrations among exposed workers were observed (table 4). In particular, fungal spore exposure was related to increased reporting of fatigue, cough with and without phlegm, wheezing/tight chest/dyspnoea and nose symptoms in a dose-dependent manner. Cough with and without phlegm was linearly related with $\log _{10}$ grain dust and $\log _{10}$ fungal spores, with similar strength (OR 3.6 and OR 3.2, respectively). Wheezing/tight chest/dyspnoea was linearly related to grain dust exposure, fungal spores, $\beta$-1,3-glucans and endotoxin, although grain dust was most important (OR 26). Fatigue was linearly related to fungal spores and $\beta-1,3$-glucans. To disentangle which component was most important, we adjusted the effect of one significant component for another pairwise in the regression models. This showed that grain dust and fungal spores were associated with cough and cough with phlegm with similar strength (OR 2.5 and 2.3, respectively, $\mathrm{p}<0.2$ ), fungal spores and glucan exposure were associated with fatigue with similar strength (OR 2.3 and 1.7, respectively, $\mathrm{p}<0.3$ ), but dust exposure was the single most important component for wheeze/ chest tightness/dyspnoea. 
Table 3 Prevalence of self-reported acute symptoms in grain and animal feed industry workers in Norway*

\begin{tabular}{|c|c|c|c|}
\hline Symptoms & $\begin{array}{l}\text { Exposed } \\
(n=56)\end{array}$ & $\begin{array}{l}\text { Referents } \\
(n=36)\end{array}$ & $\begin{array}{l}p \text { Value, } \\
\chi^{2} \dagger\end{array}$ \\
\hline Nausea and/or vomit & $1(2)$ & $2(6)$ & 0.32 \\
\hline Diarrhoea & $2(4)$ & 0 & 0.25 \\
\hline Headache & $17(30)$ & $8(22)$ & 0.39 \\
\hline Fatigue & $17(30)$ & $9(25)$ & 0.58 \\
\hline Fever attack & $6(11)$ & 0 & 0.04 \\
\hline Muscular pain & $15(27)$ & $9(25)$ & 0.85 \\
\hline Influenza/cold & $12(21)$ & $9(25)$ & 0.69 \\
\hline Sore throat & $6(11)$ & $3(8)$ & 0.71 \\
\hline Cough & $19(34)$ & $5(14)$ & 0.03 \\
\hline Cough with phlegm & $11(20)$ & $2(6)$ & 0.06 \\
\hline Cough \pm phlegm & $20(22)$ & $6(17)$ & 0.05 \\
\hline Tight chest & $3(5)$ & $4(11)$ & 0.32 \\
\hline Wheezing & $6(11)$ & 0 & 0.04 \\
\hline Dyspnoea & $7(13)$ & $3(8)$ & 0.51 \\
\hline $\begin{array}{l}\text { Wheezing/tight chest/ } \\
\text { dyspnoea }\end{array}$ & $10(18)$ & $6(17)$ & 0.59 \\
\hline Nose itch/sting & $6(11)$ & $2(6)$ & 0.38 \\
\hline Runny nose & $16(29)$ & $8(22)$ & 0.50 \\
\hline$\Sigma$ Nose symptoms & $19(34)$ & $9(10)$ & 0.43 \\
\hline Eye itch/sting & $12(21)$ & $2(6)$ & 0.04 \\
\hline Runny eyes & $6(11)$ & $1(3)$ & 0.16 \\
\hline$\Sigma$ Eye symptoms & $13(23)$ & $2(6)$ & 0.03 \\
\hline Hand itch/sting & $2(4)$ & 0 & 0.25 \\
\hline Skin rash & $4(7)$ & $1(3)$ & 0.37 \\
\hline$\Sigma$ Skins symptoms & $5(9)$ & $1(3)$ & 0.24 \\
\hline
\end{tabular}

\section{Lung function}

At baseline, the lung function as per cent of predicted showed no significant differences between exposed workers and referents (table 1). The AM FVC\% of predicted and the $\mathrm{FEV}_{1} \%$ of predicted were above $90 \%$ for all groups, except the $\mathrm{FEV}_{1} \%$ for smokers (87\%). The $\mathrm{AM} \mathrm{FEV}_{1} / \mathrm{FVC} \%$ was between $76 \%$ and $78 \%$ for all workers. The CO diffusion capacity was above $80 \%$ for all worker groups, except for smokers (77\%), atopics (79\%) and operators working in grain elevators and animal feed mills (79\%).

The cross-shift lung function changes showed no consistent associations with any of the aerosol components (table 5).

\section{Nose congestion}

All workers had moderate nose congestion, as shown by a rhinometric D-factor of 0.5 for referents and 0.6 for exposed workers (table 1).

Significant reductions of the nasal dimensions in the anterior $2 \mathrm{~cm}$ of the nasal mucosa were associated with exposure for several aerosol components (table 5). However, the doseresponse patterns were inconsistent, although a weak trend could be seen for grain dust and fungal spore exposure. No significant association with continuous log-transformed exposure variables was observed (not shown).

\section{DISCUSSION}

Exposure for several individually measured bioaerosol components in the Norwegian grain industry and health outcomes such as self-reported symptoms, lung function, CO diffusion capacity and nose congestion was studied in a cross-shift design. Bioaersosol exposure during a work shift with handling of grain and compound feed was associated with increased self-reporting of eye and airway symptoms after work shift. Bioaerosol exposure was not associated with cross-shift lung function decline, but several microbial components affected nose congestion. Self-reported airway symptoms were related to microbial components of the grain dust in a complex manner, showing differential associations between individual symptoms and the individual bioaerosol components. This suggests that each component of the grain dust may give differential effect on inhalation, which is in agreement with the a priori hypothesis.

The exposed workers reported more respiratory symptoms than the referents, which could indicate that inhalation of grain dust still might cause health problems in this industry. Symptoms such as fever attacks, fatigue, muscle pain and cough are typical symptoms of toxic pneumonitis, ${ }^{24}$ and these symptoms were in our study more often reported by exposed workers than by referents. The reporting of cough among exposed workers was more pronounced in this study compared with a cross-sectional study of animal feed workers. ${ }^{10}$

Several symptoms were associated with bioaerosol exposure levels, although the mean dust exposure level was relatively low. The lowest observed effect level (LOEL) cross-shift for cough and cough with phlegm, wheezing/tight chest/dyspnoea and eye symptoms was $1.3 \mathrm{mg} / \mathrm{m}^{3}$ inhalable grain dust, which is somewhat lower than the $2.1 \mathrm{mg} / \mathrm{m}^{3}$ no observed adverse effect level of total dust for respiratory symptoms previously reported by grain handlers. ${ }^{4}$ The LOEL of $1.6 \times 10^{4} / \mathrm{m}^{3}$ fungal spores for eye symptoms was in the same range as previously reported among Norwegian farmers, whereas the LOEL of $5.5 \times 10^{4} / \mathrm{m}^{3}$ fungal spores for cough and cough with phlegm in the present study was lower. ${ }^{25}$ The highest exposure category of endotoxin (1200-11 $\left.000 \mathrm{EU} / \mathrm{m}^{3}\right)$ and $\beta-1,3$-glucan $\left(19-150 \mu \mathrm{g} / \mathrm{m}^{3}\right)$ was associated with cough and cough with phlegm, but the linear dose-response relationship among exposed workers was not statistically significant, indicating that the exposure to endotoxin and glucan may not be as important for the reporting of these symptoms as grain dust and fungal spores. The exposure to GM $0.83(0.09-15.2) \mathrm{mg} / \mathrm{m}^{3}$ of total dust and GM $54.2(4.4-$ 744) $\mathrm{EU} / \mathrm{m}^{3}$ of endotoxin has been associated with respiratory symptoms reported by wheat harvest workers. ${ }^{26}$ In the present study, fatigue, wheezing/tight chest/dyspnoea and nose symptoms reported by exposed workers were associated with fungal spore exposure in a dose-dependent manner. However, the symptom prevalence ratios were not significantly different from the referents, so no LOEL could be identified from the categorical groups of fungal exposure levels. In spite of the high prevalence, eye symptoms were not linearly associated with any of the measured aerosol components. The fact that reported eye symptoms in exposure categories of all aerosol components nevertheless were significantly different from the referents indicates that eye symptoms may occur at low exposure levels. The present study shows LOELs at normal conditions in the grain industry. The bioaerosol exposure can be higher and dominated by different microorganisms when handling problematic materials, as shown in a case study where workers handling problematic grass seeds developed toxic pneumonitis. 2728

A lung function $<100 \%$ of predicted at baseline may indicate a detrimental effect of long-term grain dust exposure, although the cross-shift change in lung function was small and inconsistent within the study population. Cross-shift lung function reductions seemed to be associated with the highest exposure 
Table 4 Odds ratios of self-reported acute symptoms by categorical and linear bioaerosol exposure among grain and animal feed industry workers in Norway

\begin{tabular}{|c|c|c|c|c|c|c|c|c|c|c|}
\hline \multirow[b]{2}{*}{ Bioaerosol exposure } & \multicolumn{2}{|c|}{ Fatigue } & \multicolumn{2}{|c|}{ Cough \pm phlegm } & \multicolumn{2}{|c|}{$\begin{array}{l}\text { Wheeze/tight chest/ } \\
\text { dyspnoea }\end{array}$} & \multicolumn{2}{|c|}{ Nose symptoms } & \multicolumn{2}{|c|}{ Eye symptoms } \\
\hline & OR & $95 \% \mathrm{Cl}$ & OR & $95 \% \mathrm{Cl}$ & $\mathrm{OR}$ & $95 \% \mathrm{Cl}$ & OR & $95 \% \mathrm{Cl}$ & OR & $95 \% \mathrm{Cl}$ \\
\hline \multicolumn{11}{|l|}{ Grain dust $\left(\mathrm{mg} / \mathrm{m}^{3}\right)$} \\
\hline 0 (referents) & 1 & & 1 & & 1 & & 1 & & 1 & \\
\hline $0.09-0.6$ & 1.3 & 0.3 to 4.5 & $1.1^{*}$ & 0.2 to 5.3 & - & - & 0.4 & 0.08 to 2.1 & 3.6 & 0.5 to 24 \\
\hline $0.61-1.3$ & 1.1 & 0.3 to 3.8 & $3.0^{*}$ & 0.8 to 11 & $0.6+$ & 0.1 to 3.4 & 2.7 & 0.8 to 8.7 & 4.5 & 0.7 to 28 \\
\hline $1.31-14$ & 1.6 & 0.5 to 5.3 & $5.5^{*}$ & 1.5 to 20 & $4.0 \dagger$ & 1.1 to 15 & 2.0 & 0.6 to 6.5 & 7.3 & 1.3 to 41 \\
\hline per 10 -fold increase & $1.7 \S$ & 0.5 to 5.8 & 3.6 & 1.0 to 13 & 26 & 3.2 to 213 & 2.5 & 0.7 to 8.8 & 2.0 & 0.5 to 7.8 \\
\hline \multicolumn{11}{|l|}{ Endotoxin $\left(\mathrm{EU} / \mathrm{m}^{3}\right)$} \\
\hline 0 (referents) & 1 & & 1 & & 1 & & 1 & & 1 & \\
\hline $15-350$ & 1.1 & 0.3 to 3.8 & 1.8 & 0.5 to 6.9 & 0.79 & 0.1 to 4.0 & 0.8 & 0.2 to 3.0 & 3.2 & 0.5 to 21 \\
\hline $360-1000$ & 0.7 & 0.2 to 2.5 & 2.3 & 0.7 to 8.2 & 0.59 & 0.09 to 2.8 & 1.7 & 0.5 to 5.4 & 6.4 & 1.2 to 35 \\
\hline $1200-11000$ & 3.4 & 1.0 to 12 & 5.7 & 1.5 to 21.8 & 4.09 & 1.0 to 16 & 2.6 & 0.7 to 9.3 & 6.2 & 1.0 to 38 \\
\hline per 10 -fold increase $\ddagger$ & $1.8 \S$ & 0.7 to 4.4 & 1.7 & 0.7 to 4.1 & 3.8 & 1.0 to 14 & 1.4 & 0.6 to 3.4 & 1.4 & 0.5 to 3.5 \\
\hline \multicolumn{11}{|l|}{ Bacteria $\left(\# / \mathrm{m}^{3}\right)$} \\
\hline 0 (referents) & 1 & & 1 & & 1 & & 1 & & 1 & \\
\hline $0.28 \times 10^{4}-14.99 \times 10^{4}$ & 1.6 & 0.5 to 5.3 & 5.0 & 1.4 to 17 & 1.7 & 0.4 to 6.4 & 3.7 & 1.2 to 12 & 7.3 & 1.3 to 41 \\
\hline $15 \times 10^{4}-47 \times 10^{4}$ & 1.4 & 0.4 to 4.5 & 1.5 & 0.4 to 5.5 & 0.5 & 0.09 to 2.7 & 0.5 & 0.1 to 2.0 & 3.8 & 0.6 to 23 \\
\hline $58 \times 10^{4}-240 \times 10^{4}$ & 0.8 & 0.2 to 3.6 & 2.8 & 0.7 to 11 & 1.4 & 0.3 to 6.4 & 1.7 & 0.4 to 6.3 & 4.6 & 0.7 to 31 \\
\hline per 10 -fold increase $\ddagger$ & $0.8 \S$ & 0.4 to 1.6 & 0.7 & 0.3 to 1.4 & 0.7 & 0.3 to 1.6 & 0.6 & 0.3 to 1.3 & 1.0 & 0.5 to 2.3 \\
\hline \multicolumn{11}{|l|}{ Fungal spores $\left(\# / \mathrm{m}^{3}\right)$} \\
\hline 0 (referents) & 1 & & 1 & & 1 & & 1 & & 1 & \\
\hline $1 \times 10^{4}-1.5 \times 10^{4}$ & 0.7 & 0.2 to 2.7 & 1.6 & 0.4 to 5.9 & - & - & 0.5 & 0.1 to 2.1 & 5.3 & 0.9 to 30 \\
\hline $1.6 \times 10^{4}-5.4 \times 10^{4}$ & 1.1 & 0.3 to 3.8 & 2.9 & 0.8 to 11 & 1.8 & 0.5 to 6.9 & 2.2 & 0.7 to 7.1 & 6.1 & 1.1 to 35 \\
\hline $5.5 \times 10^{4}-50 \times 10^{4}$ & 3.0 & 0.9 to 10 & 5.0 & 1.3 to 19 & 2.3 & 0.6 to 9.0 & 3.0 & 0.9 to 10 & 3.9 & 0.6 to 26 \\
\hline per 10 -fold increaseł & $3.4 \S$ & 1.1 to 10 & 3.2 & 1.1 to 9.4 & 3.7 & 1.0 to 13 & 4.4 & 1.4 to 14 & 1.1 & 0.3 to 3.6 \\
\hline \multicolumn{11}{|l|}{$\beta$-1,3-Glucans $\left(\mu \mathrm{g} / \mathrm{m}^{3}\right)$} \\
\hline 0 (referents) & 1 & & 1 & & 1 & & 1 & & 1 & \\
\hline $0.30-3.60$ & 0.8 & 0.2 to 2.8 & 1.7 & 0.4 to 6.3 & 0.6 & 0.1 to 3.1 & 1.0 & 0.3 to 3.5 & 3.0 & 0.5 to 20 \\
\hline $3.70-18.9$ & 0.9 & 0.3 to 3.1 & 1.9 & 0.5 to 6.8 & 0.8 & $0.2-3.5$ & 1.4 & 0.4 to 4.5 & 6.4 & 1.2 to 35 \\
\hline $19.0-150$ & 2.6 & 1.0 to 6.9 & 9.0 & 2.2 to 37 & 2.8 & 0.7 to 11 & 3.0 & 0.8 to 11 & 6.8 & 1.1 to 43 \\
\hline per 10 -fold increase $\ddagger$ & $1.5 \S$ & 1.0 to 2.3 & 2.1 & 0.9 to 5.0 & 3.5 & 1.0 to 12 & 1.4 & 0.6 to 3.4 & 1.2 & 0.7 to 3.0 \\
\hline $\begin{array}{l}\text { Bold values indicate } p<0 \text {. } \\
\text { - too few samples in this } \\
\text { Associations are expressec } \\
{ }^{*} \text { Adjusted for gender. } \\
\text { †Adjusted for gender and } \\
\text { †Exposed workers only, } \\
\text { §OR for a 10-fold increase } \\
\text { १Adjusted for age. }\end{array}$ & gory. & 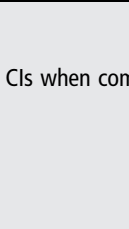 & 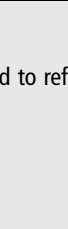 & () & 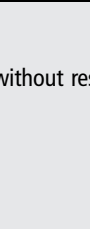 & 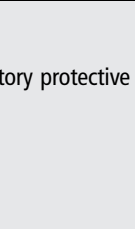 & & $n=92$ & & \\
\hline
\end{tabular}

categories of all bioaerosol components, although no linear trends were seen. Our results seem to be in line with the longterm decline in lung function that is commonly observed in studies of grain workers, whereas cross-shift effects are less consistent. Corey et $a l^{3}$ found a baseline decline of FVC, FEV maximal expiratory flow at $50 \%$ of $\mathrm{FVC}\left(\mathrm{MEF}_{50}\right)$ and maximal respiratory function at $75 \%$ of $\mathrm{FVC}\left(\mathrm{MEF}_{75}\right)$ from Monday to Friday, but increases in FVC and $\mathrm{FEV}_{1}$ cross-shifts and crossweek among grain elevator workers. Smid et $a l^{10}$ demonstrated a cross-week $\mathrm{FEV}_{1}$ decline, but no cross-shift $\mathrm{FEV}_{1}$ decline among animal feed workers. Cross-shift lung function changes have been observed among grain handlers ${ }^{4}$ and wheat harvest workers. ${ }^{26}$ Whereas cross-shift change in wheat harvest workers was not consistently related to the dust or endotoxin exposure, ${ }^{26}$ where decreases in FVC were found among grain handlers significantly correlated with increasing grain dust exposure, and workers exposed to AM 3.3 (SD 7) $\mathrm{mg} / \mathrm{m}^{3}$ of total dust had a cross-shift FVC decline of $46 \mathrm{~mL}{ }^{4}$ In five cross-sectional surveys over a period of 12 years, Chan-Yeung et $a l^{11}$ consistently found that grain workers had more respiratory symptoms and lower lung function compared with civic workers, despite a progressive reduction in dust levels in the grain elevators from GM (SD) $10.1 \mathrm{mg} / \mathrm{m}^{3}$ (3.3) in 1974 to $1.9 \mathrm{mg} / \mathrm{m}^{3}$ (3.4) in 1988. The latter is similar to the dust level in the present study.

Referents and exposed workers had moderate nose congestion as shown by a D-factor of 0.5 and 0.6, respectively. Exposed workers had cross-shift reduction in area and volume of the anterior part of the nose. This suggests a local inflammation after deposition of grain dust and its contaminants, and is supported by the association between AR nose effects and the highest two exposure categories of grain dust and fungal spores. Similar results have been reported among waste collectors, in which nasal congestion and exposure to fungal spores and $\beta-1,3$-glucans correlated with an increased level of inflammatory markers in the nasal lavage. ${ }^{29}$ All, but the grain elevator workers, showed an opposite response in the interior part of the nose. In the anterior part of the nose, the mucosa extends 
Table 5 Cross-shift changes in lung function and nose congestion by exposure category among grain and animal feed industry workers in Norway*

\begin{tabular}{|c|c|c|c|c|c|c|c|}
\hline Exposure & $\Delta \mathrm{FVC}(\mathrm{mL})$ & $\Delta \mathrm{FEV} 1(\mathrm{~mL})$ & $\Delta \mathrm{D}_{\mathrm{L}, \mathrm{co}}(\mathrm{mmol} / \mathrm{min} / \mathrm{Pa})$ & AR $\Delta \mathrm{M} 1\left(\mathrm{~cm}^{2}\right)$ & AR $\Delta \mathrm{V} 1\left(\mathrm{~cm}^{3}\right)$ & AR $\Delta \mathrm{M} 2\left(\mathrm{~cm}^{2}\right)$ & AR $\Delta \mathrm{V} 2\left(\mathrm{~cm}^{3}\right)$ \\
\hline \multicolumn{8}{|l|}{ Grain dust $\left(\mathrm{mg} / \mathrm{m}^{3}\right)$} \\
\hline 0 (referents) & 0 & 0 & 0 & 0 & 0 & 0 & 0 \\
\hline $0.09-0.6$ & $67(-60$ to 194$)$ & $57(-46$ to 161$)$ & $153(-238$ to 544$)$ & $-0.08(-0.19$ to 0.04$)$ & $-0.08(-0.31$ to 0.14$)$ & $0.03(-0.08$ to 0.14$)$ & $0.06(-0.77$ to 0.89$)$ \\
\hline $0.61-1.3$ & 65 (-50 to 181$)$ & -27 (-121 to 67$)$ & $-87(-440$ to 265$)$ & $-0.15(-0.26$ to -0.05$)$ & $-0.23(-0.43$ to -0.02$)$ & -0.005 ( -0.11 to 0.10$)$ & $0.30(-0.46$ to 1.1$)$ \\
\hline $1.31-14$ & $29(-84$ to 142$)$ & $17(-76$ to 109$)$ & $-64(-410$ to 281$)$ & $-0.12(-0.22$ to -0.02$)$ & $-0.16(-0.36$ to 0.05$)$ & $-0.03(-0.13$ to 0.07$)$ & $0.006(-0.74$ to 0.76$)$ \\
\hline \multicolumn{8}{|l|}{ Endotoxin $\left(\mathrm{EU} / \mathrm{m}^{3}\right)$} \\
\hline 0 (referents) & 0 & 0 & 0 & 0 & 0 & 0 & 0 \\
\hline $15-350$ & $46(-72$ to 165$)$ & 11 (-86 to 108$)$ & 235 (-129 to 598$)$ & $-0.18(-0.29$ to -0.08$)$ & $-0.28(-0.49$ to -0.07$)$ & $0.03(-0.07$ to 0.014$)$ & $0.40(-0.39$ to 1.19$)$ \\
\hline $360-1000$ & 103 (-5 to 211$)$ & $61(-27$ to 149$)$ & $-147(-475$ to 181$)$ & $-0.10(-0.20$ to 0.004$)$ & $-0.15(-0.34$ to 0.05$)$ & $-0.002(-0.10$ to 0.09$)$ & $-0.06(-0.78$ to 0.67$)$ \\
\hline $1200-11000$ & $-19(-144$ to 106$)$ & $-62(-164$ to 40$)$ & $-95(-480$ to 289$)$ & $-0.08(-0.19$ to 0.04$)$ & $-0.05(-0.28$ to 0.17$)$ & $-0.05(-0.15$ to 0.06$)$ & $0.09(-0.74$ to 0.91$)$ \\
\hline \multicolumn{8}{|l|}{ Bacteria (counts $/ \mathrm{m}^{3}$ ) } \\
\hline 0 (referents) & 0 & 0 & 0 & 0 & 0 & 0 & 0 \\
\hline $0.28 \times 10^{4}-14.99 \times 10^{4}$ & $65(-47$ to 177$)$ & $-14(-101$ to 73$)$ & $191(-156$ to 537$)$ & $-0.16(-0.26$ to -0.05$)$ & $-0.24(-0.45$ to -0.04$)$ & $0.02(-0.08$ to 0.12$)$ & $0.17(-0.60$ to 0.93$)$ \\
\hline $15 \times 10^{4}-47 \times 10^{4}$ & 90 ( -24 to 204$)$ & 109 (20 to 198$)$ & $-37(-384$ to 310$)$ & $-0.09(-0.19$ to 0.02$)$ & $-0.14(-0.34$ to 0.06$)$ & $-0.008(-0.11$ to 0.09$)$ & $0.11(-0.64$ to 0.86$)$ \\
\hline $58 \times 10^{4}-240 \times 10^{4}$ & $-15(-141$ to 110$)$ & $-78(-176$ to 20$)$ & $-240(-613$ to 133$)$ & $-0.11(0.23$ to 0.006$)$ & $-0.09(-0.032$ to 0.13$)$ & $-0.03(-0.14$ to 0.08$)$ & $0.09(-0.74$ to 0.92$)$ \\
\hline \multicolumn{8}{|l|}{ Fungal spores (counts $/ \mathrm{m}^{3}$ ) } \\
\hline 0 (referents) & 0 & 0 & 0 & 0 & 0 & 0 & 0 \\
\hline $1 \times 10^{4}-1.5 \times 10^{4}$ & $18(-94$ to 130$)$ & 45 (-49 to 138$)$ & $159(-200$ to 518$)$ & $-0.10(-0.20$ to 0.01$)$ & $-0.15(-0.36$ to 0.06$)$ & $0.01(-0.09$ to 0.11$)$ & $0.08(-0.67$ to 0.83$)$ \\
\hline $1.6 \times 10^{4}-5.4 \times 10^{4}$ & 143 (29 to 258 ) & $38(-57$ to 133$)$ & -138 (-497 to 221$)$ & $-0.13(-0.24$ to -0.02$)$ & $-0.13(-0.35$ to $0-08)$ & -0.05 ( -0.15 to 0.05$)$ & $-0.22(-0.99$ to 0.54$)$ \\
\hline $5.5 \times 10^{4}-50 \times 10^{4}$ & $-6(-123$ to 111$)$ & $-52(-150$ to 45$)$ & $-65(-424$ to 293$)$ & $-0.13(-0.24$ to -0.02$)$ & $-0.21(-0.43$ to 0.006$)$ & $0.03(-0.08$ to 0.13$)$ & $0.54(-0.24$ to 1.33$)$ \\
\hline \multicolumn{8}{|l|}{$\beta-1,3-$ Glucans $\left(\mu \mathrm{g} / \mathrm{m}^{3}\right)$} \\
\hline 0 (referents) & 0 & 0 & 0 & 0 & 0 & 0 & 0 \\
\hline $0.30-3.60$ & 70 (-46 to 186$)$ & 30 (-66 to 126$)$ & $44(-318$ to 407$)$ & $-0.13(-0.24$ to -0.02$)$ & $-0.17(-0.39$ to 0.04$)$ & $0.08(-0.02$ to 0.18$)$ & 0.51 ( -0.25 to 1.28$)$ \\
\hline $3.70-18.8$ & 86 (-21 to 194$)$ & $31(-59$ to 120$)$ & $19(-322$ to 360$)$ & $-0.11(-0.22$ to -0.01$)$ & $-0.20(-0.40$ to -0.01$)$ & $-0.08(-0.17$ to 0.009$)$ & $-0.26(-0.97$ to 0.45$)$ \\
\hline $19.0-150$ & $-29(-158$ to 100$)$ & -139 (-531 to 254$)$ & $-104(-500$ to 290$)$ & $-0.12(-0.24$ to 0.004$)$ & $-0.09(-0.32$ to 0.14$)$ & $0.01(-0.10$ to 0.12$)$ & 0.24 (-0.60 to 1.08$)$ \\
\hline
\end{tabular}

Values are presented as coefficients $(95 \% \mathrm{Cl})$. Bold values indicate $\mathrm{p} \leq 0.05$

"Workers without RPE were selected ( $n=92)$. 
over a smaller surface area than the interior part. Measurements of mucosal swelling in the anterior part are therefore likely to be more accurate and may better reflect an inflammatory response of dust exposure.

There were no significant difference in lung function between exposed workers and referents. This could be due to reduced acute effects of dust exposure, a kind of tolerance previously shown among pig farmers and grain handlers with long-term exposure of organic dust. ${ }^{3}{ }^{30}$ Lung function below $100 \%$ of predicted may indicate that a long-term effect of exposure has already reduced the lung function, thus supporting this view. It is also plausible that individuals sensitive to exposure change jobs to avoid hazardous exposure, leaving the ones who cope behind, thus resulting in a selection of healthy worker into exposed jobs. It may furthermore be possible that referents were sporadically exposed, which reduces the exposure contrasts between the groups. Several referents and exposed workers also had a farm or animals at home. There were no dose-response association between exposure and cross-shift lung function changes in spite of relatively high exposure levels. This may be due to a large proportion of large particles in the inhalable fraction, probably being most active in the upper airways, whereas the pulmonary effects are expected to occur from smaller particle sizes in the thoracic and respirable aerosol fraction. Although spores and bacteria are likely to protrude in the thoracic and alveolar region of the lungs, it is possible that they stick to larger fragments or are present as aggregates that deposit higher up in the airways. The associations between aerosol components, and AR nose effects and reported nose symptoms indicate that this was the case. On the other hand, spirometry and gas diffusion tests do not always reflect all processes in the development of airway diseases. Self-reporting of symptoms seemed to be more sensitive, but this may be due to the participants' greater focus on occupational exposure, resulting in overreporting of respiratory symptoms. ${ }^{31}$ Validity and reliability are general problems with questionnaires. However, we believe that specificity problems were limited in this study because the selection of questions was adapted to the study by relating to a priori defined possible effects of the relevant exposure components, and related in time to the workday. The guidance of participants during filling in the questionnaire also reduced possible misunderstandings of the questions. Given that the low lung function among workers is caused by long-term occupational exposure, the increased reporting of symptoms from the airways is in agreement with another study from occupational settings. ${ }^{32}$ In clinical settings, however, self-reported symptoms seldom correlate with objective measurements of lung function such as $\mathrm{FEV}_{1}{ }^{33}{ }^{34}$ All of the above will lead to an underestimation of exposure-response relationships in the grain elevator and compound feed mill industry, and should be considered when interpreting the results of this study. On the other hand, the selection of workers without RPE will reduce dilution problems in the exposure-response associations. Multiple testing might have led to spurious significant findings, but the number of positive associations found are greater than expected taking multiple testing into account. Significant associations between symptoms and exposure measurements are more plausible when a linear trend along the exposure categories is shown, such as between several symptoms and spore and dust exposure. The significant associations between exposure and cross-shift lung function increases and AR associations without dose-response trends are more likely to be spurious.

Previous publications from this study showed that although grain dust exposure was low, microbial exposure levels exceeded health-based recommended values ${ }^{1}$ and exposure levels varied between job groups and tasks. ${ }^{14}$ The present study shows how bioaerosol components individually and combined affected the respiratory health of workers in grain elevators, compound feed mills and transport in a complex manner. Differential linear associations between individual symptoms and the exposure level of individual bioaerosol components demonstrated this. This suggests that each component of the grain dust may give differential effect on inhalation. Fatigue and nose symptoms were strongest associated with fungal spores; cough and cough with phlegm were associated with grain dust and fungal spores with equal strength. Wheeze/tight chest/dyspnoea was strongest associated with grain dust, indicating that components of the dust not measured are involved. Some candidate effect inducers may be a large number of microbial metabolites previously detected in grain dust. ${ }^{35}$ It is also likely that some additives of animal feed could have effects.

Acknowledgements The authors thank Per Ole Huser for participating in field work and laboratory analyses and the participating companies.

Contributors MS participated in planning, acquisition of samples, interpretation of data, drafting and critical reading of the manuscript. DGE participated in planning, interpretation of data, drafting and critical reading of the manuscript. IMW participated in planning, was responsible for endotoxin and glucan analysis, and participated in interpretation of data and critical reading of the manuscript. WE was involved in planning, acquisition of samples, interpretation of data, drafting and critical reading of the manuscript. KKH participated in planning, acquisition of data, rhinometric analyses, interpretation of data and reading of the manuscript. AS is principle investigator and contributed to all parts of the planning, acquisition of data, analyses, interpretation of data and writing. Per Ole Huser (acknowledged) participated in planning, acquisition of data and microscopic analyses.

Funding This project received support from the Confederation of Norwegian Enterprise (S-2585).

Competing interests None declared.

Patient consent Obtained.

Ethics approval The Regional Ethical Committee of South-East Norway.

Provenance and peer review Not commissioned; externally peer reviewed.

Open Access This is an Open Access article distributed in accordance with the Creative Commons Attribution Non Commercial (CC BY-NC 4.0) license, which permits others to distribute, remix, adapt, build upon this work non-commercially, and license their derivative works on different terms, provided the original work is properly cited and the use is non-commercial. See: http://creativecommons.org/ licenses/by-nc/4.0/

\section{REFERENCES}

1 Halstensen AS, Heldal KK, Wouters IM, et al. Exposure to grain dust and microbial components in the Norwegian grain and compound feed industry. Ann Occup Hyg 2013;57:1105-14.

2 Broder I, Hutcheon MA, Mintz $S$, et al. Changes in respiratory variables of grain handlers and civic workers during their initial months of employment. $\mathrm{Br} J$ Ind Med 1984:41:94-9.

3 Corey P, Hutcheon M, Broder I, et al. Grain elevator workers show work-related pulmonary-function changes and dose-effect relationships with dust exposure. $\mathrm{Br} J$ Ind Med 1982;39:330-7.

4 doPico GA, Reddan W, Anderson S, et al. Acute effects of grain dust exposure during a work shift. Am Rev Respir Dis 1983;128:399-404.

5 Manfreda J, Holford-strevens V, Cheang M, et al. Acute symptoms following exposure to grain dust in farming. Environ Health Perspect 1986;66:73-80.

6 Huy T, De Schipper K, Chan-Yeung M, et al. Grain dust and lung-functiondose-response relationships. Am Rev Respir Dis 1991;144:1314-21.

7 Pahwa P, Dosman JA, McDuffie HH. Effects of grain dust on lungs prior to and following dust remediation. J Occup Environ Med 2008;50:1394-400.

8 Post W, Heederik D, Houba R. Decline in lung function related to exposure and selection processes among workers in the grain processing and animal feed industry. Occup Environ Med 1998;55:349-55.

9 Spurzem JR, Romberger DJ, Von Essen SG. Agricultural lung disease. Clin Chest Med 2002;23:795-810. 
10 Smid T, Heederik D, Houba R, et al. Dust- and endotoxin-related acute lung function changes and work-related symptoms in workers in the animal feed industry. Am J Ind Med 1994;25:877-88.

11 Chan-Yeung M, Dimich-Ward H, Enarson DA, et al. Five cross-sectional studies of grain elevator workers. Am J Epidemiol 1992;136:1269-79.

12 Jagielo PJ, Thorne PS, Watt JL, et al. Grain dust and endotoxin inhalation challenges produce similar inflammatory responses in normal subjects. Chest 1996:110:263-70.

13 Health Council of the Netherlands. Grain dust. Health-based recommended occupational exposure limit. The Hague: Health Council of the Netherlands, 2011; publication no. 2011/13.

14 Straumfors A, Heldal KK, Wouters IM, et al. Work tasks as determinants of grain dust and microbial exposure in the Norwegian grain and compound feed industry. Ann Occup Hyg 2015;59:724-36.

15 Naclerio RM, Bachert C, Baraniuk JN. Pathophysiology of nasal congestion. Int J Gen Med 2010;3:47-57.

16 van der Wal A. Comparative measurements of the total dust concentration at the work place with different samplers-part 1. Staub-Reinhalt Luft 1983:43:292-4.

17 Medical Research Council. Standardized questionnaires on respiratory symptoms: Medical Research Council's Committee on the Aetiology of Chronic Bronchitis. $\mathrm{Br}$ Med J 1960:2:1665.

18 Miller MR, Hankinson J, Brusasco V, et al. Standardisation of spirometry. Eur Respir J 2005:26:319-38.

19 Langhammer A, Johnsen R, Gulsvik A, et al. Forced spirometry reference values for Norwegian adults: the bronchial obstruction in Nord-Trøndelag study. Eur respir J 2001;18:770-9.

20 Macintyre N, Crapo RO, Viegi G, et al. Standardisation of the single-breath determination of carbon monoxide uptake in the lung. Eur Respir $J$ 2005;26:720-35.

21 Marrades RM, Diaz 0, Roca J, et al. Adjustment of DLCO for hemoglobin concentration. Am J Respir Crit Care Med 1997;155:236-41.

22 Cotes JE, Chinn DJ, Reed JW. Lung function testing: methods and reference values for forced expiratory volume (FEV1) and transfer factor (TL). Occup Environ Med 1997;54:457-65.

23 Chaaban M, Corey JP. Assessing nasal air flow: options and utility. Proc Am Thorac Soc 2011;8:70-8.
24 Von Essen S, Fryzek J, Nowakowski B, et al. Respiratory symptoms and farming practices in farmers associated with an acute febrile illness after organic dust exposure. Chest 1999;116:1452-8.

25 Eduard W, Douwes J, Mehl R, et al. Short term exposure to airborne microbial agents during farm work: exposure-response relations with eye and respiratory symptoms. Occup Environ Med 2001;58:113-8.

26 Viet SM, Buchan R, Stallones L. Acute respiratory effects and endotoxin exposure during wheat harvest in Northeastern Colorado. Appl Occup Environ Hyg 2001;16:685-97.

27 Madsen AM, Tendal K, Schlunssen V, et al. Organic dust toxic syndrome at a grass seed plant caused by exposure to high concentrations of bioaerosols. Ann Occup Hyg 2012;56:777-88.

28 Madsen AM, Zervas A, Tendal K, et al. Microbial diversity in bioaerosol samples causing ODTS compared to reference bioaerosol samples as measured using Illumina sequencing and MALDI-TOF. Environ Res 2015;140:255-67.

29 Heldal KK, Halstensen AS, Thorn J, et al. Upper airway inflammation in waste handlers exposed to bioaerosols. Occup Environ Med 2003;60:444-50.

30 Palmberg L, Larssson BM, Malmberg P, et al. Airway responses of healthy farmers and nonfarmers to exposure in a swine confinement building. Scand J Work Environ Health 2002;28:256-63.

31 Bakke PS, Hanoa R, Gulsvik A. Relation of occupational exposure to respiratory symptoms and asthma in a general population sample: selfreported versus interview-based exposure data. Am J Epidemiol 2001;154:477-83.

32 Søyseth $\mathrm{V}$, Johnsen $\mathrm{HL}$, Henneberger PK, et al. Increased decline in pulmonary function among employees in Norwegian smelters reporting work-related asthma-like symptoms. J Occup Environ Med 2015;57:1004-8.

33 Ståhl E. Correlation between objective measures of airway calibre and clinical symptoms in asthma: a systematic review of clinical studies. Respir Med 2000;94:735-41.

34 Buffels J, Degryse J, Heyrman J, et al. Office spirometry significantly improves early detection of COPD in general practice: the DIDASCO study. Chest 2004;125:1394-9.

35 Straumfors A, Uhlig S, Eriksen GS, et al. Mycotoxins and other fungal metabolites in grain dust from Norwegian grain elevators and compound feed mills. World Mycotoxin J 2015;8:361-73. 